\title{
TINITALY/01: a new Triangular Irregular Network of Italy
}

\author{
Simone Tarquini, Ilaria Isola, Massimiliano Favalli, Francesco Mazzarini, Marina Bisson, \\ Maria Teresa Pareschi and Enzo Boschi \\ Istituto Nazionale di Geofisica e Vulcanologia, Sezione Pisa, Italy
}

\begin{abstract}
A new Digital Elevation Model (DEM) of the natural landforms of Italy is presented. A methodology is discussed to build a DEM over wide areas where elevation data from non-homogeneous (in density and accuracy) input sources are available. The input elevation data include contour lines and spot heights derived from the Italian Regional topographic maps, satellite-based global positioning system points, ground based and radar altimetry data. Owing to the great heterogeneity of the input data density, the DEM format that better preserves the original accuracy is a Triangular Irregular Network (TIN). A Delaunay-based TIN structure is improved by using the DEST algorithm that enhances input data by evaluating inferred break-lines. Accordingly to this approach, biased distributions in slopes and elevations are absent. To prevent discontinuities at the boundary between regions characterized by data with different resolution a cubic Hermite blending weight $S$-shaped function is adopted. The TIN of Italy consists of $1.39 \times 10^{9}$ triangles. The average triangle area ranges from 12 to about $13000 \mathrm{~m}^{2}$ accordingly to different morphologies and different sources. About $50 \%$ of the model has a local average triangle area $<500 \mathrm{~m}^{2}$. The vertical accuracy of the obtained DEM is evaluated by more than 200000 sparse control points. The overall Root Mean Square Error (RMSE) is less than $3.5 \mathrm{~m}$. The obtained national-scale DEM constitutes an useful support to carry out accurate geomorphological and geological investigations over large areas. The problem of choosing the best step size in deriving a grid from a TIN is then discussed and a method to quantify the loss of vertical information is presented as a function of the grid step. Some examples of DEM application are outlined. Under request, an high resolution stereo image database of the whole Italian territory (derived from the presented DEM) is available to browse via internet.
\end{abstract}

Key words Italy - triangular irregular network DEM - interpolation method

\section{Introduction}

Digital Elevation Models (DEMs) are essential for many geological and environmental studies. Topography plays a fundamental role in hydrological and morphological studies, in risk and hazard evaluations, and to identify lineaments and faults (Martz and Garbrecht, 1995; Stevens et al., 1999; Favalli et al., 1999; Kuhni

Mailing address: Dr. Simone Tarquini, Istituto Nazionale di Geofisica e Vulcanologia, Sezione Pisa, Via della Faggiola 32, 56100 Pisa, Italy; e-mail: tarquini@pi.ingv.it and Pfiffner, 2001; Székely and Karátson, 2004; Ganas et al., 2005). The accuracy of a DEM is essential for environmental analyses (Kenward et al., 2000; Chaplot et al., 2006) and for natural phenomena simulation (Stevens et al., 2003; Favalli et al., 2005, 2006a). Owing to the complexity of the geodynamic and morphological context and to the extensive urbanization, Italian territory is often exposed to hazardous events (e.g., Pareschi et al., 2000a,b).

Italy is administratively partitioned into 20 Regions and each Regional territory is divided into several sub-territorial authorities (i.e. Provinces and River Basin Authorities). Local administrations followed different methodologies and attained an uneven detail in elevation data collection according to different means and/or environmental priorities. 
This paper is primarily focused on the creation of a global seamless high resolution DEM of the whole Italian territory from an heterogeneous dataset. In recent decades new technologies have allowed the creation of several DEMs at continental and regional scales (Hutchinson, 1996; Liu et al., 1999; NED-USGS, 2000; Farr and Kobrick, 2000; Bamber et al., 2001; Swisstopo, 2001). We used suitable interpolation algorithms and procedures to create as accurate a model as possible from the available data. The DEM is provided in a TIN format and we present procedures for data merging and elaboration too. The output dataset is named TINITALY/01.
Since DEMs are often requested in grid format, we carefully investigate the loss of accuracy in converting a TIN into elevation grids with variable step size.

Finally, we mention some examples of applications of our DEM.

\subsection{Previous DEMs}

Before our effort, four DEMs of the whole Italian territory were available: they are listed and briefly described in the following (in order of decreasing step size):
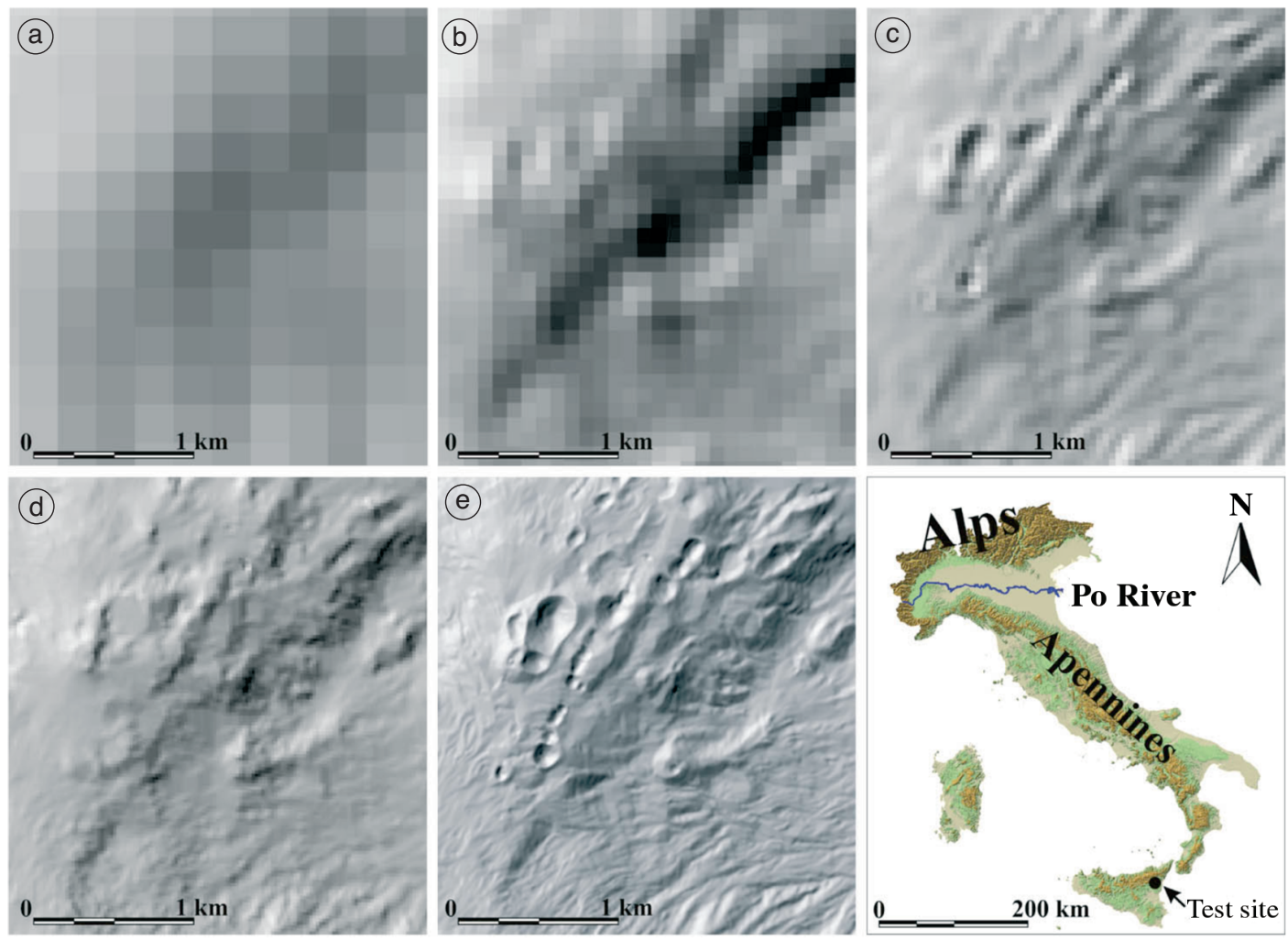

Fig. 1a-e. Shaded relief images (illumination from northwest) of samples of the available DEMs of Italy, representing the northeast summit of Mt. Etna in Sicily. Bottom right panel: the map of Italy with the main mountainous areas and the test site location. North to the top. From the lower (a) to the higher (e) horizontal grid resolution: a) Archivio delle Quote Medie with a grid cell of $240 \mathrm{~m}$; b) SRTM with a grid cell of $90 \mathrm{~m}$; c) Terra-Italy/CGR with a grid cell of $40 \mathrm{~m}$; d) IGM-1:25000 with a grid cell of $20 \mathrm{~m}$; e) TINITALY/01 resampled to a $10 \mathrm{~m}$ grid cell. 
i) Archivio delle Quote Medie - This DEM was obtained by simple linear interpolation of contour lines digitized from the 1:25000 maps of the Istituto Geografico Militare (IGM) (fig. 1a). The database is organized into 280 tiles (Carrozzo et al., 1985) subsequently merged into an unique matrix with a step of about $240 \mathrm{~m}$ (Pike et al., 1990; Reichenback et al., 1993). This model was used as a framework for morphological and hydrogeological applications at regional scale (Onorati et al., 1992; Guzzetti and Reichenbach, 1994; Guzzetti et al., 1997, 1999).

ii) SRTM-Italy - A global Terrain Model was released on May 2004 by the National Aeronautics and Space Administration (NASA) and the National Imagery and Mapping Agency (NIMA) (Farr and Kobrick, 2000; <http://www.jpl.nasa.gov/srtm > accessed on July 2007) in the context of the Shuttle Radar Topography Mission (SRTM). SRTM acquires two simultaneous images by a dual Spaceborne Imaging Radar (SIRC) and dual $X$-band Synthetic Aperture Radar $(X$ SAR) configured as a baseline interferometer. The data are expressed in geographic coordinates and are referenced to the WGS84 Geoid. More than $90 \%$ of the Italian land surface is covered by SRTM data. The SRTM DEM in Italy is averaged to 3 " spacing ( $~ 90 \mathrm{~m}$ posting) from the original 1" spacing. The absolute horizontal and vertical precision is $20 \mathrm{~m}$ (error at $90 \%$ confidence) and 16 $\mathrm{m}$ (error at $90 \%$ confidence), respectively (fig. $1 b)$. Vegetation is not considered in these error estimates and it is expected to introduce systematic positive RMSEs in the SRTM elevations (Falorni et al., 2005).

iii) Terra-Italy/CGR - This DEM of Italy was produced by the Compagnia Generale Ripreseaeree (Compagnia Generale Ripreseaeree SpA, $<$ http://www.blomasa.com/cgr/it $>$ accessed on July 2007) by aerophotogrammetry. Aerial photos at 1:70000 scale were acquired at an average altitude of $10000 \mathrm{~m}$ a.s.l. by using a Wild camera RC20 (focus $152.82 \mathrm{~mm}$ ). Digital elevation data, step size $40 \mathrm{~m}$, are arranged in tiles of $185 \times 144$ grid cells. Altimetric precision is less than $5 \mathrm{~m}$ in $95 \%$ of cases (fig. 1c).

iv) IGM-1:25000 DEM - This DEM was created by IGM (Istituto Geografico Militare, Florence, Italy, $2^{\circ}$ Direzione della produzione, Servizio Elaborazione Dati; <www.igmi.org>, accessed on July 2007) and is obtained from contour lines and spot heights derived from the IGM 1:25000 maps (fig. 1d). These data are projected in UTM ED50 and are organized in tiles of 3 different sizes $\left(10 \times 10 \mathrm{~km}^{2}\right.$ with a 20 $m$ resolution; $10^{\prime}$ Long $\times 6^{\prime}$ Lat with a $1^{\prime \prime}$ resolution; 20' Long $\times 12^{\prime}$ Lat with a $3^{\prime \prime}$ resolution). The elevation value of each grid point was mainly calculated by an inverse-distance weighted algorithm, averaging the 8 nearest neighbor elevations on contour lines or spot heights. These 8 points are the nearest ones in the eight sectors defined by the N-S and E-W directions and their bisectors. Sometimes, the interpolation algorithm introduces biased topographic features, with an octahedral pattern (Favalli and Pareschi, 2004). IGM guarantees a vertical accuracy of 7$10 \mathrm{~m}$ estimated as tested by using control points.

\section{TINITALY/01: input data and processing methods}

\subsection{Data sources}

The used input data came from different sources and were collected with the help of the Italian Ministry of the Environment, the Italian Regions and Provinces, the River Basin Authorities and IGM (fig. 2).

The main data sources were:

i) Technical Cartography (CTR 5000 maps at 1:5000 scale, fig. 2). Contour lines (5 m interval) and spot heights derived from aerial photogrammetric surveys were available in a digital format. For some areas, gullies and ridges determined through photogrammetry were available as 3D polylines. Vertical precision is $1.2 \mathrm{~m}$ for spot heights and $2 \mathrm{~m}$ for contour lines. Planimetric precision is $2 \mathrm{~m}$ (in $95 \%$ of cases).

ii) Technical Regional Cartography (CTR 10000 maps at 1:10000 scale, fig. 2). Contour lines (10 m interval) and spot heights derived from aerial photogrammetric surveys were available in a digital format. For some areas, gullies and ridges, determined through photogrammetry, were available as 3D polylines. Vertical precision is $1.8 \mathrm{~m}$ for spot heights and $3.5 \mathrm{~m}$ for contour lines. Planimetric precision is $4 \mathrm{~m}$ (in $95 \%$ of cases). 


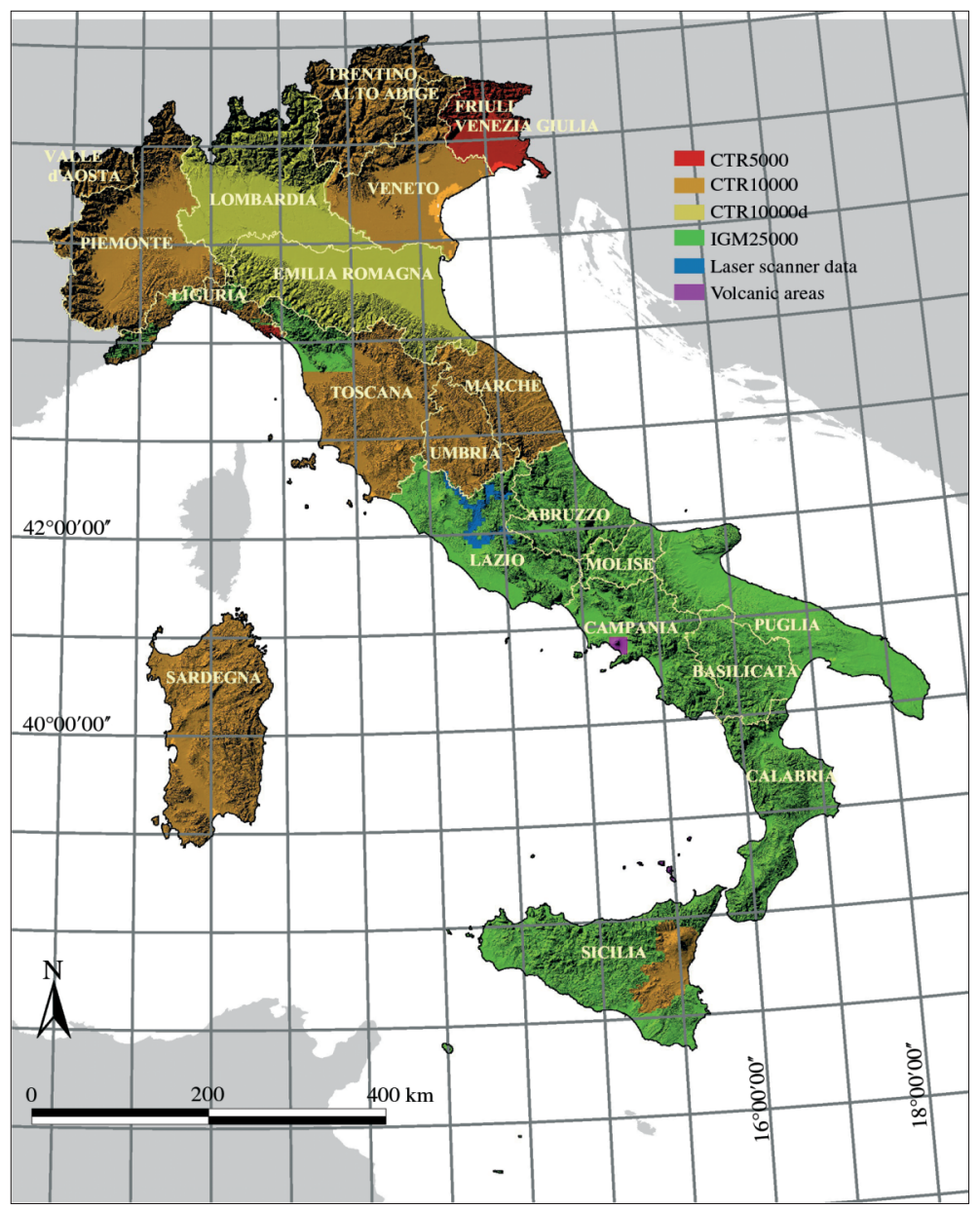

Fig. 2. The resolution of input data sources is not homogeneous over the Italian territory. Data resolution may even vary within some regions (e.g., Liguria Region).

iii) Technical Regional Cartography (CTR 10000 maps, at 1:10000 scale, fig. 2). Vertical precision is $1.8 \mathrm{~m}$ for spot heights and $3.5 \mathrm{~m}$ for contour lines (50 $\mathrm{m}$ interval). Planimetric precision is $5 \mathrm{~m}$.

iv) IGM data (IGM 25000 maps, at 1:25000 scale, fig. 2). Contour lines (25 $\mathrm{m}$ interval) and spot heights with variable vertical precision (1-7 $\mathrm{m})$.

v) Airborne laser-scanner altimetry data with submetric precision (fig. 2); Tevere, Aniene,
Nera-Velino river beds in the Lazio Region (Tevere River Basin Authority, 1997-1998).

vi) Sparse Global Positioning System (GPS) data with centimeter precision (Autonomous Province of Bolzano-Alto Adige).

vii) Additional detailed input data were used for some volcanic areas (fig. 2). For the Vesuvian area contour lines and spot heights at a nominal scale of 1:2000 (Pareschi et al., 2000b) with a vertical precision of $0.6 \mathrm{~m}$ (spot heights) and 0.9 $\mathrm{m}$ (contour lines) and with planimetric precision 
of $1.2 \mathrm{~m}$ (in $95 \%$ of cases) were used. For portions of the Aeolian Islands (Achilli et al., 1998; Bisson et al., 2003) and Etna (Favalli et al., 2005) detailed input data with an altimetric precision of less than 0.5-1 $\mathrm{m}$ were used.

viii) The coastline was digitized from the IT2000 orthophotos $1 \mathrm{~m}$ pixel size, $4 \mathrm{~m}$ planimetric accuracy (after Compagnia Generale Ripreseaeree SpA, <http://www.blomasa.com/cgr/it> accessed on July 2007).

The input datasets were originally available in the following map projections and datums:

- SI 1940, Gauss Boaga (Transverse Mercator), Hayford 1909 Ellipsoid, Monte Mario, Zone 1 (west) and Zone 2 (east), elevation data are referred to Mean Sea Level (MSL).

- Universal Transverse Mercator Projection, European Datum ED50 with the International Hayford (1909) Ellipsoid, Potsdam, Zones 32 and 33, elevation data referred to MSL.

The adopted coordinate systems for TINITALY/01 is Universal Transverse Mercator/World Geodetic System 1984 (UTM-WGS84): the 32 zone (for Western Italy) and the 33 zone (for
Eastern Italy). Coordinate transformation from other systems to the adopted one were performed using the Traspunto software (Maseroli, 2002) based on the IGM95 Italian network, Europe ETRS89 Reference System (Surace, 1997). The planimetric precision of this coordinate transformation is $20 \mathrm{~cm}$ on the average, with a maximum error less than $0.85 \mathrm{~m}$.

\subsection{The triangulation method}

Several interpolation techniques are used for the generation of raster-format DEMs, the main are: inverse distance weighting, ordinary kriging, universal kriging, multiquadratic radial basis function and regularized spline with tension. Many authors have compared the reliability of these different methods (e.g., Chaplot et al., 2006) concluding that the best choice is not univocal because it strongly depends on the input data density.

The TIN structure perfectly deals with the variable density of the input data preserving details and avoiding redundancy.

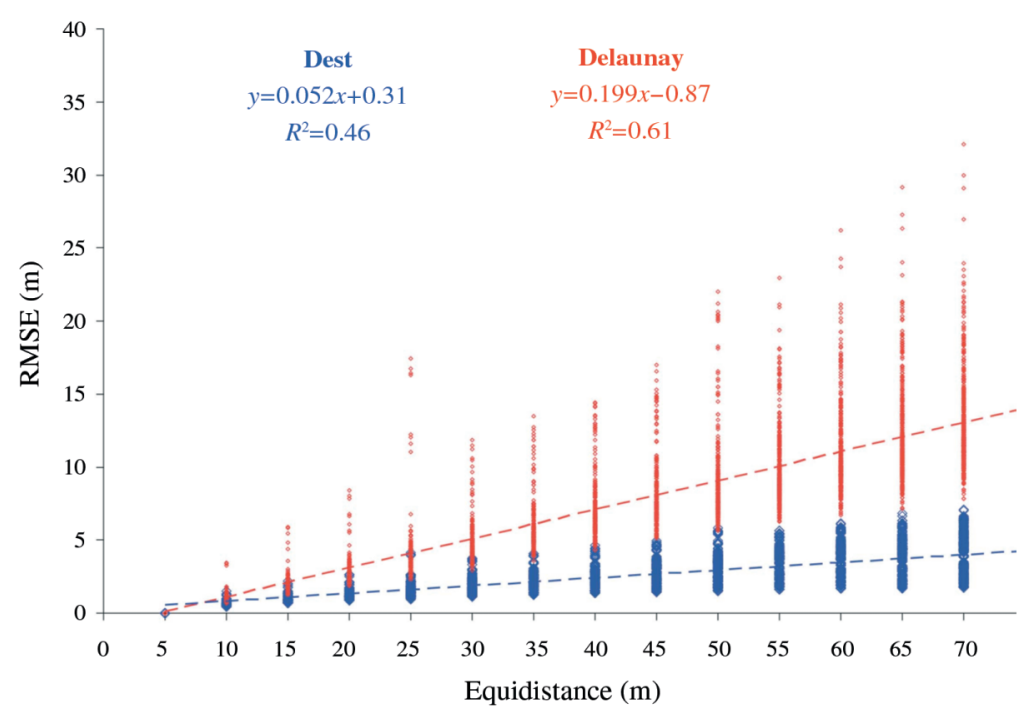

Fig. 3. Plot of RMSE versus equidistance computed through the DEST (open blue diamond) and Delaunay approach (open red diamond). The original equidistance was $\Delta z_{0}=5 \mathrm{~m}$. The regression line slope represents the average errors in interpolation as a function of equidistance. DEST has an average RMSE of about $5 \%$ of the equidistance, whereas Delaunay has an average RMSE of $20 \%$. 
The most diffuse method to build a TIN is Delaunay tessellation (Macedonio and Pareschi, 1991). This method minimizes the sum of the maximum internal angle of all the triangles. Moreover, no point of the set is inside the circumcircle of any triangle of such a tessellation. The Delaunay method provides satisfactory results if input points are randomly scattered, but if they have a pattern in a plane, false flat morphological features related to the triangle whose all vertices belong to the same contour line are introduced, and bias effects occur. This especially happens where contours lines have high curvature. We adopted the DEST algorithm (Favalli and Pa-reschi, 2004) to avoid this problem. The basic idea by DEST is the computation of ridges and gullies identified as the skeleton of the regions where biased distributions in slopes and elevations arise after a «simple» Delaunay tessellation. DEST computes medial lines (skeleton) equidistant from the boundary of the flat region constituted by local network of flat triangles. The $Z$ value of each skeletal node is interpolated between adjacent contour lines.

All the original input points (spot heights and elevation contours) plus the computed ones along break-lines (skeleton lines) are used to create an improved triangular mesh. When input data have a random distribution (for example when provided by a laser scanning survey), DEST performs a straightforward Delaunay tessellation.

To further evaluate the performance of the two algorithms, DEST and Delaunay, we compared RT (a reference TIN built using contour lines with the equidistance $\Delta z_{0}=5 \mathrm{~m}$ ) with a series of re-built TINs obtained from a subset of the input data $\left(\Delta z_{n}=\right.$ ranging from 10 to $70 \mathrm{~m}$, by $5 \mathrm{~m}$ ): the closer the sub-set TIN to the RT, the better the triangulation algorithm.

This procedure was applied once using the DEST algorithm and then the Delaunay one over 29 test areas representing the Italian landforms types. Subsequently the elevation RMSE was computed considering about $6 \times 10^{6}$ control points for each test area and the results are shown in fig. 3. As an overall result the DEST algorithm introduced an average RMSE corresponding to about $5 \%$ of the equidistance between the subset contour lines, whereas the Delaunay approach yielded an average RMSE of about $20 \%$.

\subsection{Data processing}

At a first step the huge amount of collected data was considered in separate batches to obtain preliminary elevation models of single regions (step 1, fig. 4). To allow easier data management, the input dataset was organized according to $10 \times 10,5 \times 5$ or $2.5 \times 2.5 \mathrm{~km}^{2}$ tiles, depending on the density of the input data (the denser the data the smaller the tile size).

Error correction involved a preliminary automatic procedure (batch processing) followed by a supervised one.

Original data redundancy and anomalies were corrected through batch processing. For example, when the distance between a spot height and a contour line was lower than the planimetric precision of topographic contour points, the considered spot height was automatically removed.

The supervised correction of the vector database was performed through a series of editing tools and automatic and semi-automatic filters (the TINITALY/01 toolbox) created using the ArcView 3.3® package. A team of GIS-skilled operators applied these utilities and time after time tuned the filters parameters considering both different input vector types (i.e. equidistance) and different morphologies (i.e. steep slopes in the case of close contour lines, or smooth slopes for spaced contours).

During the supervised correction, areas where the input data vector were unusable had been integrated using raster IGM cartographic maps at a nominal scale of 1:25000. To preserve boundary continuity, each tile was merged with the adjacent ones, corrected, and then cut updating the whole database. This procedure ensures that tile borders are free from edgematching errors.

The second step (fig. 4) consists of the merging of the vector databases belonging to the Regions of the same UTM zone. In this way we obtained the country model arranged in two zones (32 and 33).

As a final step the 33 zone database, reprojected to 32 zone, was merged with the resident 32 zone database obtaining the thorough seamless TIN of Italy (step 3, fig. 4).

Particular attention was paid to prevent seams along boundary between areas with different spa- 
tial resolution (steps 2 and 3, fig. 4). These discontinuities were minimized by a cubic Hermite blending weight $S$-shaped function, controlling adverse edge effects and preserving elevation continuity across the boundaries (Liu et al., 1999) (fig. 5a,b).

A trial-and-error loop was followed throughout all the correction procedure (the «check» circle, fig. 4).

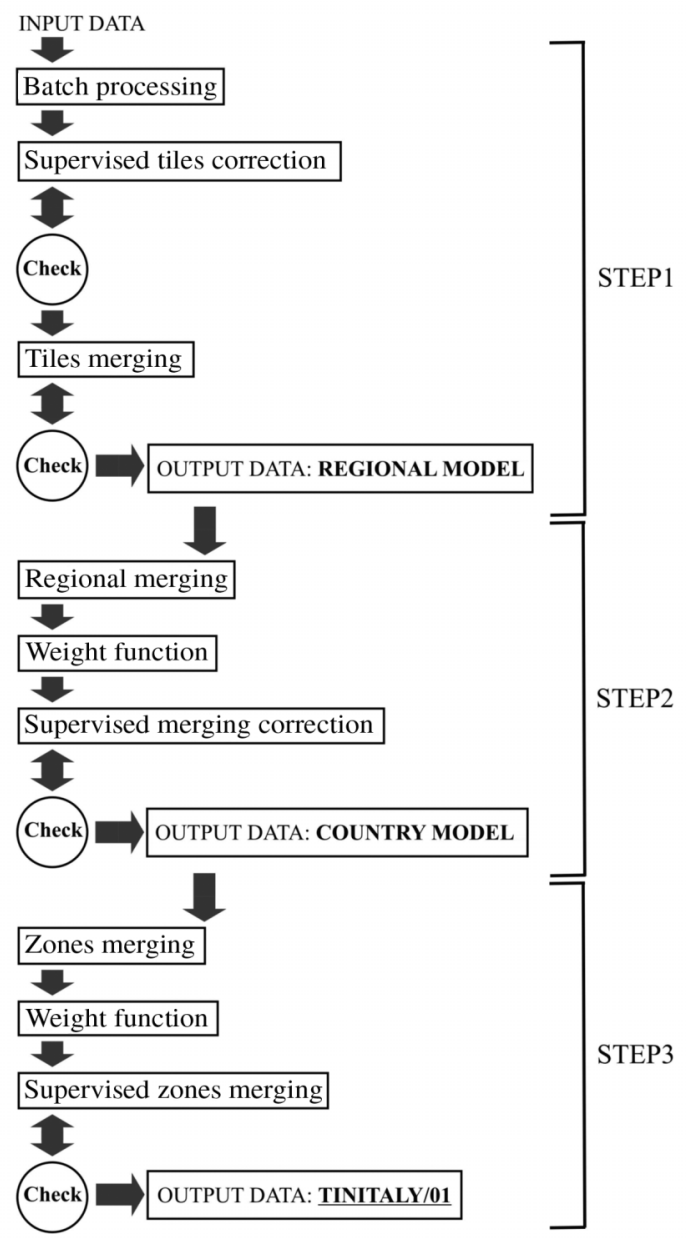

Fig. 4. Flow chart of data processing procedure for the creation of the TINITALY/01. Data check implies the creation of shaded relief images where artifacts appear as erratic scars, anomalous ditches, sharp peaks or deep ridges.


Fig. 5a,b. a) Perspective view of two contiguous areas with different spatial resolutions: in the bottom left portion the Toscana Region with denser contour lines and, in the upper portion, the Emilia Romagna Region with lower resolution data. In the yellow belt merging between the two areas is forced. Red lines represent tile edges, the tiles in foreground are $2.5 \times 2.5 \mathrm{~km}^{2}$. The thin solid blue line is the administrative boundary between the two Regions. b) The same view of (a) showing the obtained DEM.

\section{The seamless TIN of Italy}

As already mentioned, the TIN of Italy is available in the UTM-WGS84 coordinate system, zones 32 and 33. Elevations are referred to mean sea level.

The main characteristics of TINITALY/01 are resumed in table I for each Region and for the whole territory.

The node density of TINITALY/01 is shown in fig. 6. Density is mainly controlled both by 


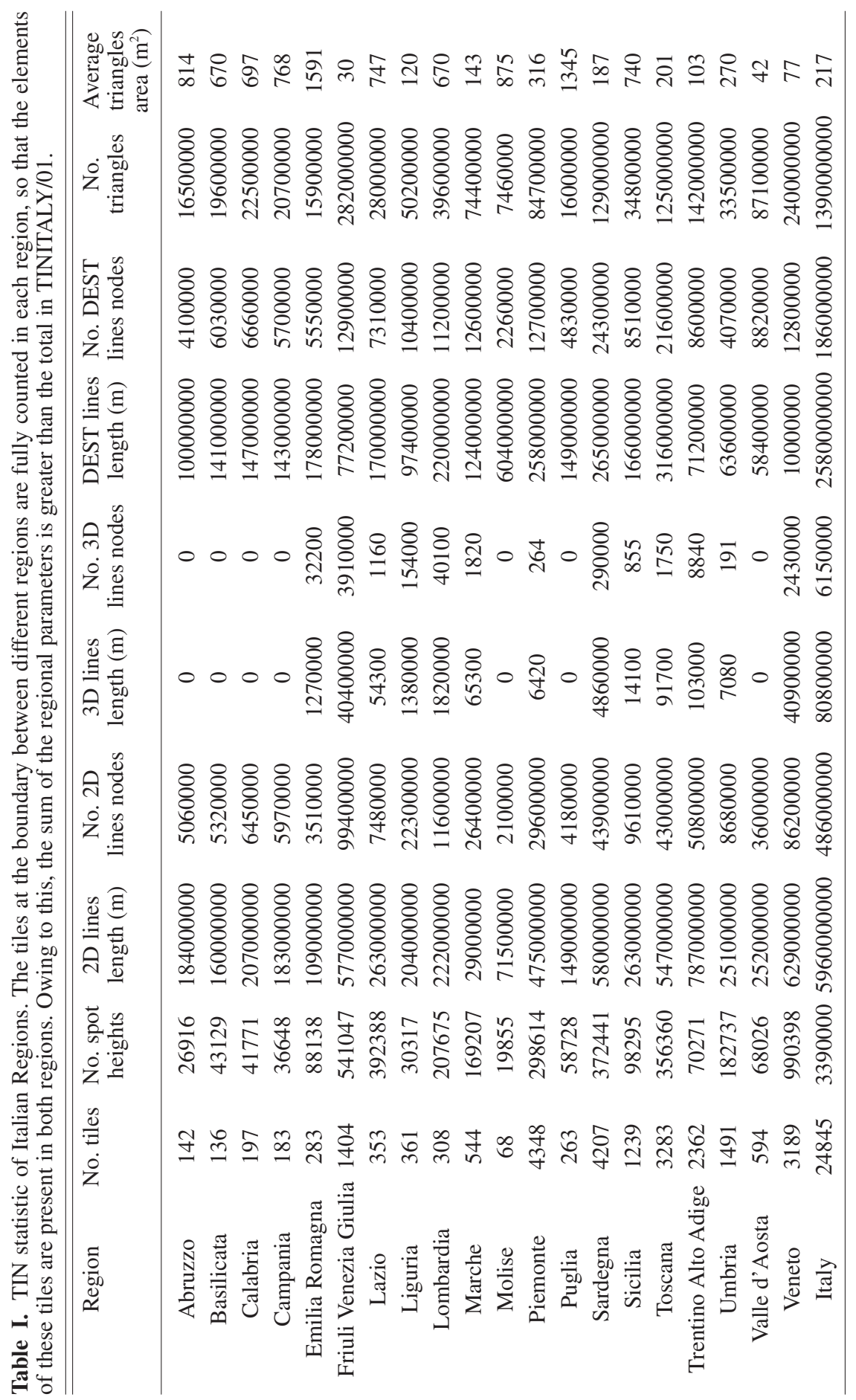




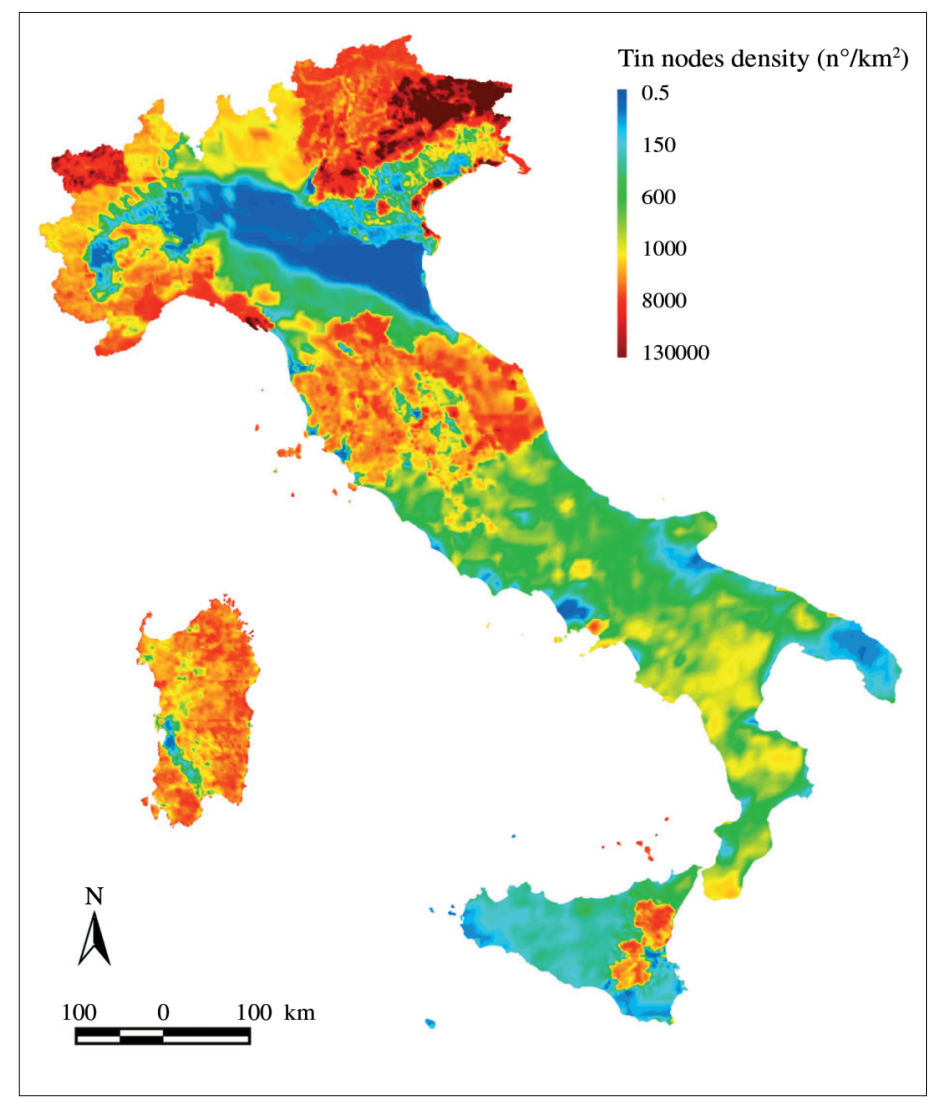

Fig. 6. The node density of the TINITALY/01 database has been derived triangulating the number of nodes per $\mathrm{km}^{2}$ of all the tiles. Note the uneven distribution over the Italian territory. The resolution of the original input data source (fig. 2) clearly exerts a strong control on the TIN node density distribution. The number of TIN triangles is roughly twice the number of TIN nodes all over the model, so values reported on the scale bar of the figure can be directly converted to obtain the local average TIN triangle areas.

the nominal scale of input data and by the heterogeneity of the Italian landscape. Morphology evidently controls the density of features. The lowest densities are attained in the major Italian plains (the Po Valley in the North, the plain areas in Campania and Puglia Regions), whereas the highest densities are found in the high relief areas of Valle D'Aosta and Eastern Alps. In morphologically homogeneous areas, for example South-East Sicily (South Italy) and Liguria Region (North Italy), the node density of the TIN is related mainly to the nominal scale of input data (figs. 2 and 6).
The average triangle area of the TIN range from 12 to about $13000 \mathrm{~m}^{2}$ accordingly to different landscapes and different sources. Table II summarize this value obtained over representative sample areas (400 to $3000 \mathrm{~km}^{2}$ wide) scattered throughout the entire database.

\subsection{TIN vertical accuracy}

We have estimated the vertical accuracy of TINITALY/01, by using independent sets of control points: 
Table II. The Average TIN Triangle Area (ATTA) for different data sources and different landscapes.

\begin{tabular}{clc}
\hline Data source & Landscape & ATTA $\left(\mathrm{m}^{2}\right)$ \\
\hline CTR 5000 & Mountains & 12.0 \\
CTR 10000 & Mountains & 72.9 \\
CTR 10000d & Mountains & 310 \\
IGM 25000 & Mountains & 656 \\
CTR 5000 & Hills & 30.3 \\
CTR 10000 & Hills & 187 \\
CTR 10000d & Hills & 597 \\
IGM 25000 & Hills & 919 \\
CTR 5000 & Plains & 197 \\
CTR 10000 & Plains & 1165 \\
CTR 10000d & Plains & 13269 \\
IGM 25000 & Plains & 1782 \\
\hline
\end{tabular}

a) 200000 points from the more recently available Technical Regional Cartography (vertical precision $\pm 1.80 \mathrm{~m}$ ) scattered over extra urban areas (EUA);

b) 1000 points form the LiDAR data set (L) (Mazzarini et al., 2005) (vertical precision $<1 \mathrm{~m}$ ).

The direct comparison of TINITALY/01 and these control points revealed a mean RMSE in elevation of less than $3.2 \mathrm{~m}$ for the entire investigated area. The great variability in the mean RMSE (0.84 m Friuli Venezia Giulia; 5.99 m Calabria) of Italian regions is mainly due to the different sources of input data (table III and fig. 2).

Another set of points to evaluate the vertical accuracy of TINITALY/01 was derived from photogrammetric analysis of stereo pairs and consists of 1800000 points (vertical precision

Table III. The elevation RMSE of the TIN for the 20 Regions of Italy.

\begin{tabular}{cccc}
\hline \hline Region & EUA RMSE $(\mathrm{m})$ & UA RMSE $(\mathrm{m})$ & Source \\
\hline Abruzzo & 4.43 & 5.26 & IGM 25000 \\
Basilicata & 4.32 & 5.97 & IGM 25000 \\
Calabria & 5.99 & 6.91 & IGM 25000 \\
Campania & 3.20 & 4.98 & IGM 25000 ${ }^{(1)}$ \\
Emilia Romagna & 5.05 & 2.74 & CTR 10000d \\
Friuli Venezia Giulia & 0.84 & 1.36 & CTR 5000 \\
Lazio & 5.92 & 5.89 & IGM 25000 ${ }^{(1)}$ \\
Liguria & 5.35 & 2.63 & IGM 25000 ${ }^{(1)}$ \\
Lombardia & 3.68 & 4.83 & CTR 10000d d \\
Marche & 2.08 & 2.38 & CTR 10000d 0 \\
Molise & 3.76 & 4.51 & IGM 25000 \\
Piemonte & 1.76 & 2.13 & CTR 10000d \\
Puglia & 2.14 & 2.52 & IGM 25000 \\
Sardegna & 1.97 & 2.33 & CTR 10000d \\
Sicilia & 3.19 & 5.35 & IGM 25000 ${ }^{(1)}$ \\
Toscana & 2.05 & 2.83 & CTR 10000d ${ }^{(1)}$ \\
Trentino Alto Adige & 2.76 & 2.09 & CTR 10000d \\
Umbria & & 2.01 & CTR 10000d \\
Valle d'Aosta & & 1.91 & CTR 10000d \\
Veneto & & 1.25 & CTR 10000d \\
Italy & 3.20 & 4.29 & \\
\hline ETNA (Eastern Sicily) & 2.44 & & \\
\hline
\end{tabular}

(1) These regions source data sets have different resolution (fig. 2). 
$\pm 0.80 \mathrm{~m}$ ) concentrated in the Urban Areas (UA) of several Italian cities. In this case the urban data source strongly affected the resulting RMSE. In particular, the average value for the whole territory of Italy is $4.3 \mathrm{~m}$ (table III). This very high value is explained as the source data used in TINITALY/01 are generally poor in urban areas where the very heterogeneous and unevenly distributed manmade features can affect data precision. Regions with low-resolution da- ta sources (1:25000) show high RMSE values ranging from $5.9 \mathrm{~m}$ in Calabria to $2.1 \mathrm{~m}$ in Puglia, whereas regions at 1:10000 scale have RMSE values ranging from $2.8 \mathrm{~m}$ in Trentino Alto Adige to $1.8 \mathrm{~m}$ in Piemonte.

All the sets of control points used to test the vertical accuracy of the TIN of Italy are shown in fig. 7 and grouped into 3 different categories according to their source (Extra Urban Areas, LiDAR and Urban Areas).

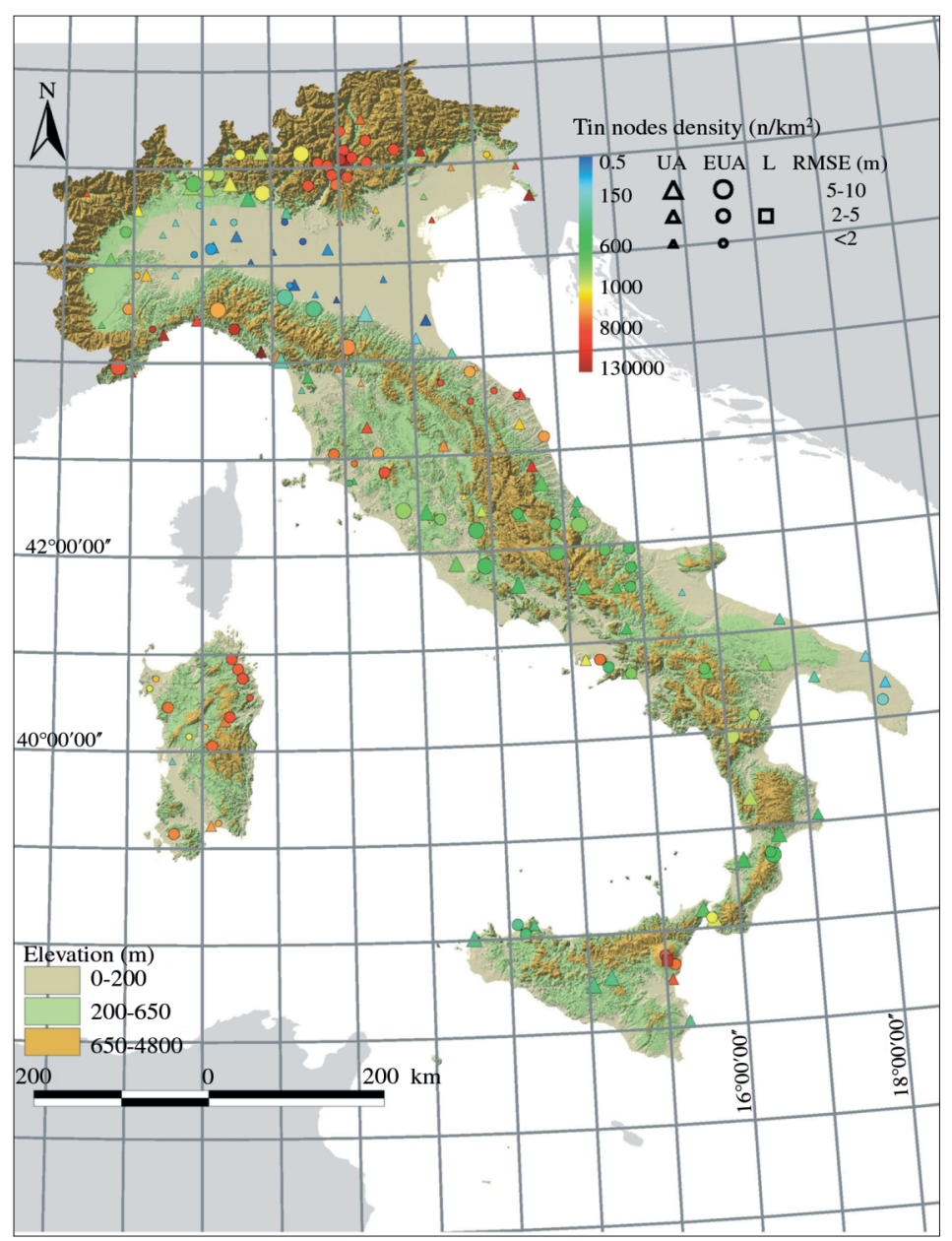

Fig. 7. Vertical accuracies of TINITALY/01 plotted over a shaded relief image of Italy. Estimates were done by using control point sets in Extra Urban Areas (EUA, circles), Urban Areas (UA, triangles) and LiDAR (L, squares). Colors represent the local TIN nodes density, increasing from blue to red. The size of the symbols relate to the vertical accuracy of the TINITALY/01 elevations, according to the top-right legend of the figure. 


\section{TIN to regular grid}

In terrain analysis a raster model is usually preferred to a TIN one because of two main reasons:

- the use of matrix elaboration;

- the great compatibility with most software.

In this work we computed the grid cell values projecting each cell center (grid node) onto the TIN surface, so the grid is a straightforward sampling of the TIN.

The key question is to evaluate how close the derived grid is to the input TIN. The answer implies the evaluation of the discrepancy between these two models. For this purpose we compared two different methods tested over a sample square area $\left(6.25 \mathrm{~km}^{2}\right)$ : the Fast Fourier Transform (FFT) approach (e.g., Liu et al., 1999) and a simple statistic-based method (fig. 8a).

\subsection{The wavelength analysis}

The FFT approach provides information on the relative amount of height variation at different wavelengths or spatial frequencies (Pike and Rozema, 1975; Gallant et al., 1994).
First of all we derived a reference grid with a cell size much smaller than the local average TIN node spacing (cell size $\delta x_{o}=0.3052 \mathrm{~m}$, average TIN node spacing $\sim 4 \mathrm{~m}$ ), so this grid $\left(G \delta x_{o}\right)$ is a good representation of the original TIN. The number of nodes of $G \delta x_{o}$ is $N^{2}$.

Then we have obtained the power spectrum applying the FFT on $G \delta x_{o}$. Refining the approach of Liu et al. (1999), the adopted landscape reference function was not the mean of the test area, but the best fitting plane $\alpha$, so that data were detrended and the variance was not masked by first order components. Owing to data de-trending, the basic component (i.e. the constant) of the FFT power spectrum was zero, thereby giving greater weight to data scattering. According to the Parseval-Rayleigh theorem, the sum of the variation computed in the spatial domain equals the total power (sum of the squared amplitudes) computed in the frequency domain. At a cut-off frequency $k_{\text {cut-off }}$, the total loss of information $\sigma_{\text {LOST }}^{2}\left(k_{\text {cut-off }}\right)$ can be calculated through

$$
\sigma_{\text {LOST }}^{2}\left(k_{\text {cut-off }}\right)=\sum P\left(k_{1}, k_{2}\right) \quad k_{1}, k_{2}=k_{\text {cut }- \text { off }} \cdots \frac{N}{2}
$$

where $P\left(k_{1}, k_{2}\right)$ is the power component of fre-
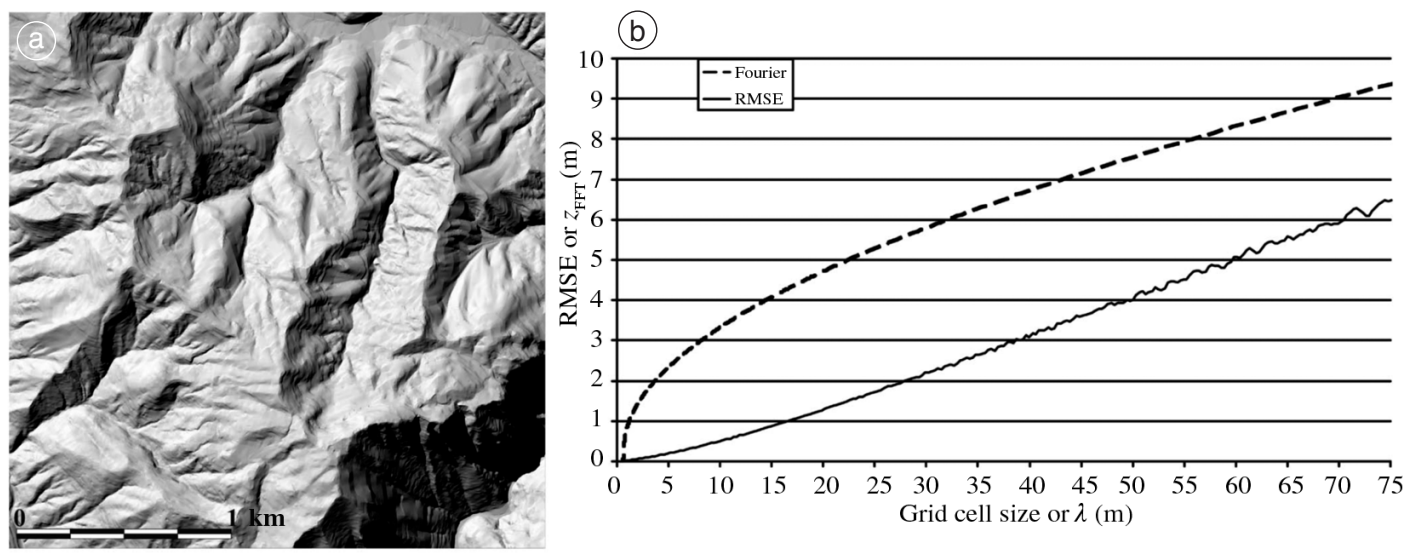

Fig. 8a,b. Comparison between the FFT and the RMSE. a) Shaded-relief image of the tile used as a test site inside the Friuli Region (bottom left coordinates: $x=825000 \mathrm{~m} ; y=5130000 \mathrm{~m}$ in UTM WGS84 zone 32). b) Plot of the elevation RMSE versus grid cell size $\delta x$ (solid line) and of the error in elevation $z_{\mathrm{FFT}}$ as estimated by the FFT (dashed line) versus the cut-off wavelengths $\lambda$ of the landscape features. 
quencies $\left(k_{1}, k_{2}\right)$. $\sigma_{\text {LOST }}$ represents the cumulative discrepancies in elevation between $G \delta x_{o}$ and a filtered grid obtained discarding frequencies $>k_{\text {cut-off }}$ for the $N^{2} G \delta x_{o}$ nodes. According to the FFT approach, the resulting average error in elevation ( $z_{\mathrm{FFT}}$ ) obtained in a $G \delta x_{o}$ node by neglecting wavelengths (i.e. feature dimensions) below the grid step $\delta x$ is therefore

$$
z_{\mathrm{FFT}}=\frac{\sigma_{\mathrm{LOST}}}{N^{2}} .
$$

The $z_{\text {FFT }}$ obtained as a function of cut-off wavelengths $\lambda$ of the landscape features was the dashed line in fig. $8 \mathrm{~b}$.

To validate the obtained error in elevation, we related the wavelength $\lambda$ to the grid cell size $\delta x_{i}$ in the following procedure. We evaluated the discrepancy between $G \delta x_{o}$ and a series of grids $\left(G \delta x_{i}\right)$ derived from the same test TIN using an increasing step size $\delta x_{i}$ linearly varying from $2 \delta x_{o}$ to $75 \mathrm{~m}\left(2 \delta x_{o}, 3 \delta x_{o} \ldots 75 \mathrm{~m}\right)$; then we calculated the difference in elevation between each derived grid $G \delta x_{i}$ and $G \delta x_{o}$ at each $G \delta x_{o}$ nodes obtaining an elevation RMSE based on an extremely rich sampling $\left(G \delta x_{o}\right.$ nodes $=67$, $108,864)$, that warrants a very accurate evaluation of the $G \delta x_{0}-G \delta x_{i}$ discrepancies.

At the end of this procedure we plotted elevation RMSE versus grid cell size $\delta x_{i}$ (solid line in fig. 8b). Comparing the dashed and the solid lines, it results that, at short wavelengths (high cut-off frequencies), the FFT overestimates the error in respect to the RMSE.

Furthermore, the FFT approach can be misleading when applied to topographic data, because it assumes a stationary signal (i.e. the landscape mean, variance and higher order moments should all be independent on location), but this is not the case for topographic data. Another problem with the Fourier transform is that often the sine functions are not a good representation of the fundamental shapes occurring in the landscape, so a good localization in scale is impossible. Non-sinusoidal shapes produce harmonics at shorter wavelengths which can mask the contribution of smaller features at those wavelengths. This also implies that the Fourier transform may represent a single feature in the landscape with a substantial number of sinusoidal components and, conversely, a single component may contain contributions from several surface features.

\subsection{The statistical analysis}

A different evaluation of the «optimal» grid step can be calculated through a statistical evaluation of the discrepancies between the TIN and grids with different cell sizes (similarly to the above calculated $G \delta x_{o}-G \delta x_{i}$ discrepancies). This evaluation was accomplished by analyzing the elevation RMSE between the TIN and the grids for given sets of sample points. The elevation of a sample point was obtained by projecting this point onto the TIN, and the corresponding elevation onto the grid was computed through bilinear interpolation of the grid nodes.

Three different sets of points were used to evaluate the match between the grid and the original TIN in 40 sample areas representing the Italian territory:

- The first set consisted of random points.

- The second set was the nodes of the TIN itself; the contributions of these points were weighted according to the area of the corresponding Voronoi polygon (Watson, 1981; Favalli and Pareschi, 2004). A Voronoi polygon in a TIN lattice defines a polygon whose interior includes all points in the plane which are closer to a particular TIN point than to any other. This set includes ridges and valleys points as inferred by the DEST algorithm. At these points local slope discontinuities of the TIN occur.

- The third set was the barycentres of each triangle in the TIN; the contribution of these points was weighted according to the area of the corresponding triangle. By definition these points have zero curvature on the TIN, and they locally maximize the distance from the edges of the TIN mesh.

The RMSE between TIN and grids for these three sets of points was calculated for different cell sizes (from $5 \mathrm{~m}$ to $200 \mathrm{~m}$ by $5 \mathrm{~m}$ steps). In each sample area the RMSE value was highest for the set of TIN nodes, lowest for the set of barycentres and intermediate for the set of random points. Considering that each grid approximates the TIN, the RMSE was highest when the control points lay near the vertices, or edges, of the TIN trian- 

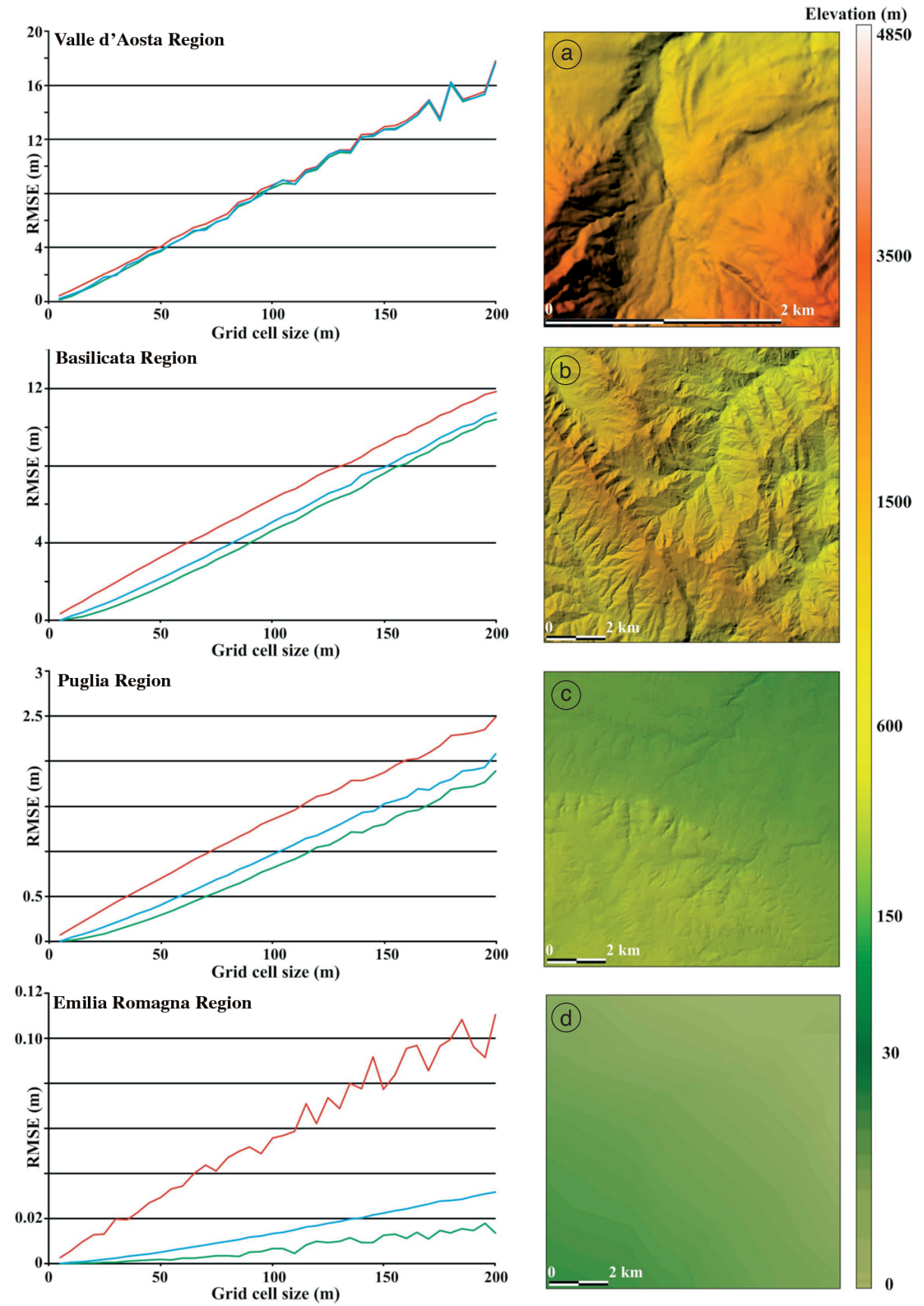

Fig. 9a-d. RMSE between TIN and grid for the TIN node set (red line), the barycentre set (green line) and the random point set (blue line). The grid cell size step is $5 \mathrm{~m}$. a) Valle d'Aosta; b) Basilicata; c) Puglia; d) Emilia Romagna. Morphological data are listed in table III. 
Table IV. Characteristics for the four cases presented in fig. 9a-d.

\begin{tabular}{ccccc}
\hline Sampled regions & $\begin{array}{c}\text { Tile side } \\
(\mathrm{km})\end{array}$ & $\begin{array}{c}\text { Node density } \\
\left(\text { Node } / \mathrm{km}^{2}\right)\end{array}$ & $\begin{array}{c}\text { Triangle density } \\
(\text { Triangle/km })^{2}\end{array}$ & $\begin{array}{c}\text { RMSE height } \\
(\mathrm{m})\end{array}$ \\
\hline Valle d'Aosta & 2.5 & 12543 & 24726 & 317 \\
Basilicata & 10 & 985 & 1946 & 160 \\
Puglia & 10 & 577 & 1138 & 63 \\
Emilia Romagna & 10 & 1.22 & 1.55 & 9.4 \\
\hline
\end{tabular}

gles, and lowest when the control points were as distant as possible from the edges of the TIN mesh (the barycentres of the TIN triangles).

Figure 9a-d and table IV show four test areas representing different data densities and different morphologies: the absolute RMSE decreases from Valle d'Aosta to Emilia Romagna, while the relative difference between the nodes RMSE and the barycentres RMSE increases.

These results show that a suitable amount of random points yields a consistent average RMSE and that the random set allows a significant test.

\subsection{The accuracy of the grids for TINITALY/01}

Applying the procedure described at 4.2 we evaluated the error introduced in deriving a grid at variable step size for all of Italy. The procedure generated more than 33 million random points through the 24847 tiles of the TINITALY/01 database. The random points local density is proportional to the local density of TIN nodes. Figure 10a-f represents the RMSE distribution over the Italian territory for a grid cell size of $10 \mathrm{~m}, 40 \mathrm{~m}$ and $100 \mathrm{~m}$. The diagram in fig. $10 \mathrm{~d}$ shows the cumulative computation of the RMSE for the whole territory of Italy with cell size varying from $5 \mathrm{~m}$ to $200 \mathrm{~m}$ by $5 \mathrm{~m}$ steps. By plotting slope versus cell size (fig. 10d), it results that the RMSE increases very fast in the 5-30 $\mathrm{m}$ range, according to a second order polynomial regression

$$
\begin{gathered}
\mathrm{RMSE}=0.0011 \delta x^{2}+0.0304 \delta x+0.5421 \\
R^{2}=0.999
\end{gathered}
$$

where $\delta x$ is the cell size in meters and $R^{2}$ is the correlation coefficient.
In the 30-200 $\mathrm{m}$ interval, the relationship between RMSE and grid cell size becomes linear according to the regression function

$\mathrm{RMSE}=0.0877 \delta x-0.2185 R^{2}=0.999$

In order to investigate the significance of the threshold where RMSE changes its trend, the same analysis was performed on a grid derived from 50 m equidistance contour lines (Emilia Romagna Region) and from $5 \mathrm{~m}$ equidistance contour lines (Friuli Venezia Giulia Region). In both cases (fig. 10e,f), the trend change in RMSE versus $\delta x$ function seems related to the contour interval of the original data (figs. 10e, f respectively for $50 \mathrm{~m}$ and $5 \mathrm{~m}$ contour intervals). Considering the adopted random sampling over the entire territory, contour lines spaced more than $25 \mathrm{~m}$ give a statistical contribution $<<1 \%$, and the trend change at about $30 \mathrm{~m}$ (fig. 10d) seems related to the contribution of the $25 \mathrm{~m}$ equidistance contour lines.

\section{Examples of applications of the model}

A major portion of the Italian territory is affected by severe natural hazards (floodings, landslides, debris-flows, volcanic eruptions, earthquakes). When dealing with environmental studies, a detailed DEM is essential for risk management, allowing numerical symulations and derived hazard maps (Kenward et al., 2000; Pareschi et al., 2002; Stevens et al., 2003).

The grid step largely influences both the spatial pattern and the frequency distribution of derived topographic attributes, such as slope and catchment areas, or tectonic feature detection (e.g., Moore et al., 1991; Zhang and Montgomery, 1994; Zhou and Liu, 2004). 
(a)
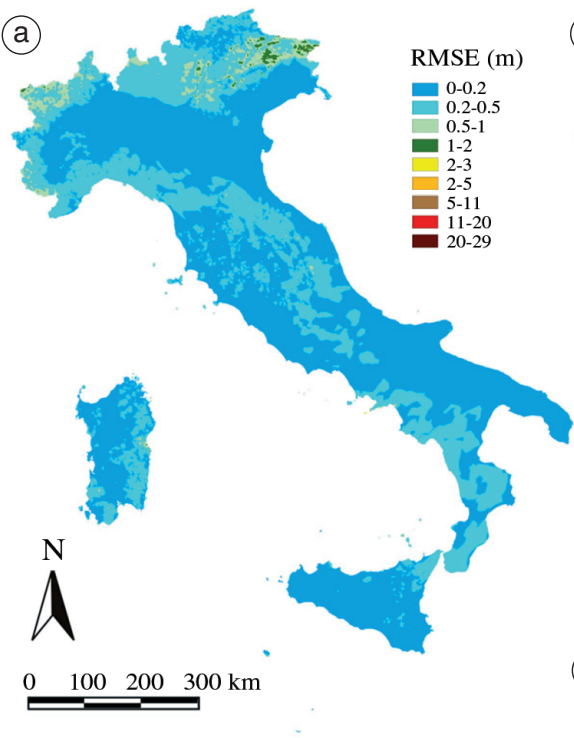

(๑)

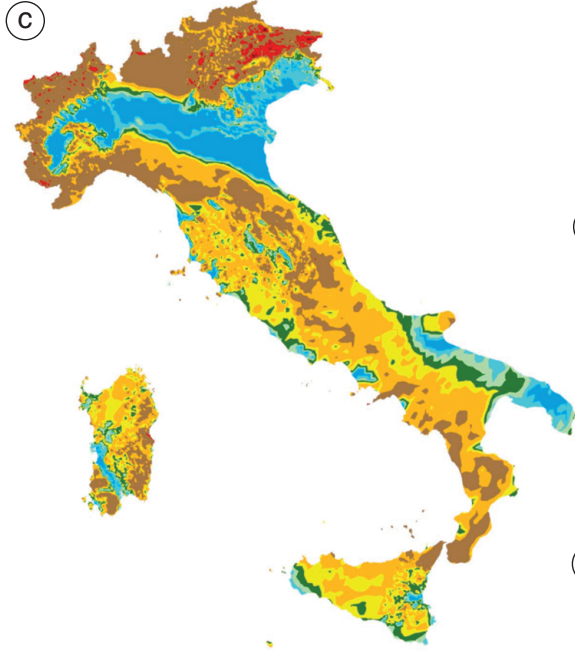

(b)

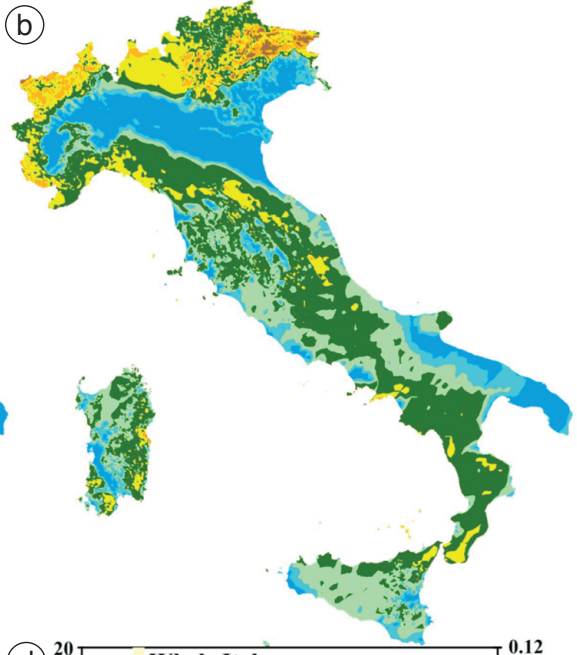

(d)

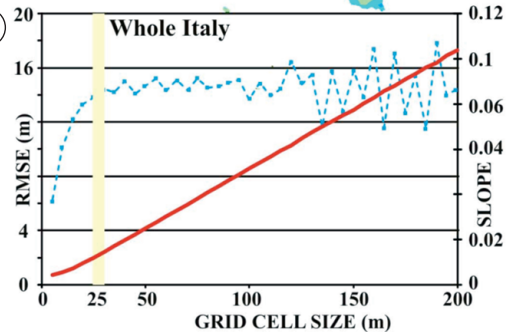

(e)

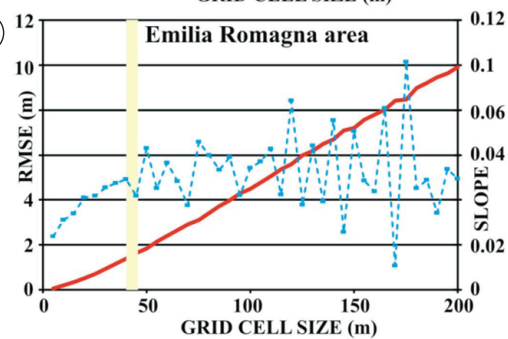

(f)

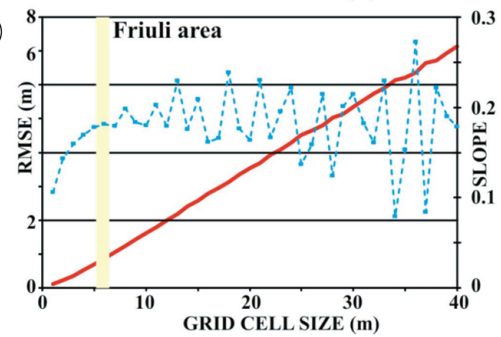

Fig. 10a-f. Distribution over the Italian territory of the RMSE derived from the transformation of the TINITALY/01 into a grid: a) map of the RMSE for a grid cell of $10 \mathrm{~m}$; b) map of the RMSE for a grid cell of $40 \mathrm{~m}$; c) map of the RMSE for a grid cell of $100 \mathrm{~m}$; d) RMSE versus grid cell size diagram (solid red line) and its slope (dashed blue line) for the whole Italian territory; e) RMSE and its slope versus grid cell size diagram for the Emilia Romagna Region; f) RMSE and its slope versus grid cell size diagram for the Friuli Venezia Giulia Region. In all the cases, the estimated RMSE shows two different trends at a threshold marked in the figures by a vertical yellow strip. 
We present here some applications based on the TINITALY/01 DEM:

- In the Vesuvian area (South Italy), the watershed extraction revealed that the volcanic apparatus create a sort of natural dam hampering the drainage of the Nola basin towards the sea (East flank of the volcano) highlighting a flooding risk (Favalli et al., 2006b).

- In the western flanks of the Apenninic Chain in Campania (South Italy) the model was applied to quantify morphometric parameters of steep basins providing insight for debris flow hazard assessment (Pareschi et al., 2000a).

- In the areas covered by volcanoclastic deposits (i.e. Campania Region) the extraction of slope maps allowed a preliminary zonation of areas potentially exposed to debris flows hazard (slope $>25^{\circ}$ ) (Bisson et al., 2007).

- In Sicily (South Italy) the TINITALY/01 model was used to orthorectify Landsat images allowing the extraction of burned area and providing a method to assess fire-related debris flow hazard (Bisson et al., 2005).

\section{Conclusions}

A new detailed DEM of the whole Italian territory is presented (TINITALY/01). It currently represents the Italian national-scale model with the highest accuracy. We discussed the procedures that allowed the creation of this seamless DEM starting from a very large heterogeneous input dataset. We demonstrated that the adopted DEST interpolation algorithm (Favalli and Pareschi, 2004) provides an unbiased triangulation.
The TIN of Italy consists of 1390 million of triangles and its accuracy is evaluated by using ground control points. The map of the vertical accuracy is presented and discussed considering both the local morphology and the input data density. The obtained RMSE ranges from $0.1 \mathrm{~m}$

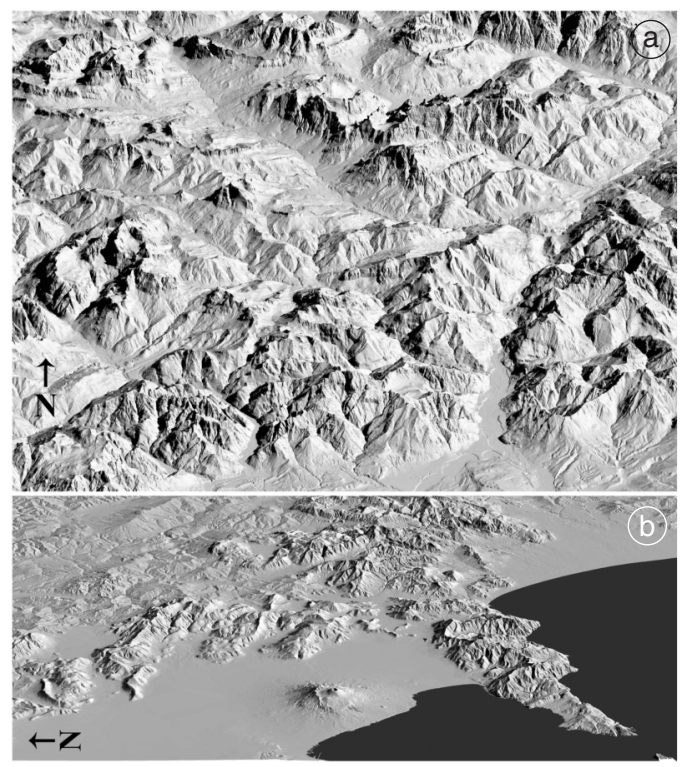

Fig. 11a,b. Perspective views derived from the TINITALY/01 data base: a) the Dolomiti Mountains (Alps, NE Italy) and b) the area around Vesuvius Volcano (Campania Region). The approximate length of the foreground base of the perspective images are respectively 32 and $55 \mathrm{~km}$.

Table V. The views of the TINITALY/01 DEM on line (<https://webgis.pi.ingv.it $>$ temporary address).

\begin{tabular}{ccccccc}
\hline \hline Viewed area & \multicolumn{2}{c}{ Illumination } & \multicolumn{3}{c}{ View point } & GRID cell size $(\mathrm{m})$ \\
& Azimuth & Elevation & Azimuth & Elevation & Distance $(\mathrm{km})$ & \\
\hline Alps & $90^{\circ} \mathrm{N}$ & $45^{\circ}$ & $147^{\circ} \mathrm{N}$ & $30^{\circ}$ & 30000 & 10 \\
Apennines & $315^{\circ} \mathrm{N}$ & $45^{\circ}$ & $225^{\circ} \mathrm{N}$ & $30^{\circ}$ & 30000 & 10 \\
Sardegna & $315^{\circ} \mathrm{N}$ & $45^{\circ}$ & $255^{\circ} \mathrm{N}$ & $30^{\circ}$ & 30000 & 10 \\
Sicily & $315^{\circ} \mathrm{N}$ & $45^{\circ}$ & $225^{\circ} \mathrm{N}$ & $30^{\circ}$ & 30000 & 10 \\
Val d'Aosta & $315^{\circ} \mathrm{N}$ & $45^{\circ}$ & $90^{\circ} \mathrm{N}$ & $90^{\circ}$ & $\approx$ infinite & 5 \\
Abruzzo & $315^{\circ} \mathrm{N}$ & $45^{\circ}$ & $90^{\circ} \mathrm{N}$ & $90^{\circ}$ & $\approx$ infinite & 10 \\
Friuli & $315^{\circ} \mathrm{N}$ & $45^{\circ}$ & $90^{\circ} \mathrm{N}$ & $90^{\circ}$ & $\approx$ infinite & 5 \\
\hline
\end{tabular}


to $6 \mathrm{~m}$, the average RMSE for all Italy is less than $3.5 \mathrm{~m}$.

The problem of the loss of vertical accuracy in deriving a grid from a TIN is then discussed. In general, when a grid is derived from a TIN, the FFT yields a biased information on the accuracy involved. We propose a statistical method to evaluate the TIN to grid interpolation accuracy and we provide equations that give resampling errors as a function of the grid step $\delta x$.

We presented a series of applications of the DEM for environmental assessment.

Several perspective and zenithal stereo images (anaglyph mode) have been generated from the DEM (fig. 11a,b and table V) and arranged for online navigation using the freeware Common Gateway Interface MapServer (<http://mapserver.gis.umn.edu $>$ accessed on July 2007). On request, internet navigators can browse stereo views of the Italian landscape at $<$ https://webgis.pi.ingv.it> (temporary address).

\section{Acknowledgements}

We kindly thank the Italian Administrations that delivered the data, including the Italian Ministry of Environment, Istituto Geografico Militare, the Regions and Provinces of Italy and the River Basin Authorities. The work was partially supported by the Italian Ministry of Environment.

\section{REFERENCES}

Achilli, V., P. Baldi, L., Baratin, C. Bovini, E. Ercolani, S. GANDOLFI, M. ANZIDEI and F. RiguZZI (1998): Digital photogrammetric survey on the island of Vulcano, Acta Vulcanol., 10, 1-5.

Bamber, J.L., S. Ekholm and W. Krabill (2001): A new, high resolution digital elevation model of Greenland fully validated with airborne laser altimeter data, $J$. Geophys. Res., 106 (B4), 6733-6745.

Bisson, M., M. Favalli, A. Mori, F. Mazzarini, M.T. PARESCHI and L. SinAPI (2003): A morphometric model of the Aeolian Islands (Italy), Nuovo Cimento, 26 (4), 417-435.

Bisson, M., M. Favalli, A. Fornaciai, F. Mazzarini, I. IsoLA, G. ZANChETTA and M.T. PARESCHI (2005): A rapid method to assess fire-related debris flow hazard in the mediterranean region: an example from Sicily (Southern Italy), Int. J. Appl. Earth Obs. Geoinf., 7, 217-231.

Bisson, M., M.T. PAReschi, G. ZancheTta, R. Sulpizio and R. SANTACRoce (2007): Volcaniclastic debris flow oc- currences in the Campania Region (Southern Italy) and their relation to Holocene-Late Pleistocene pyroclastic fall deposits: implications for large scale hazard mapping, Bull. Volcanol., doi: 10.1007/s00445-007-0127-4.

Carrozzo, M.T., D. Luzio, C. Margiotta, T. Quarta, F. Zuanni, A. Chirenti and A.M. Tundo (1985): Data base of mean height values for the whole Italian landmass and surrounding areas: determining and statistical analysis, Boll. Geod. Sci. Affini, 44 (1), 38-56.

Chaplot, V., F. Darboux, H. Bourennane, S. Leguédois, N. Silvera and K. Phachomphon (2006): Accuracy of interpolation techniques for the derivation of digital elevation models in relation to landform types and data density, Geomorphology, 77, 126-141.

Falorni, G., V. TAles, E.R. Vivoni, R.L. Bras and K.S. AmARATUNGA (2005): Analysis and characterization of the vertical accuracy of digital elevation models from the Shuttle Radar Mission, J. Geophys. Res., 110, F02005, doi: 10.1029/2003JF000113.

FARR, T.G. and M. KoBrick (2000): Shuttle radar Topography Mission produces a wealth of data, Eos, Trans. Am. Geophys. Un., 81 (48), 583-585.

FAvalli, M. and M.T. PARESCHI (2004): Digital elevation model construction from structured topographic data: the DEST algorithm, J. Geophys. Res., 109, F04004, doi: 10.1029/2004JF000150.

Favalli, M., F. Innocenti, M.T. Pareschi, G. Pascquaré, F. Mazzarini, S. Branca, L. Cavarra and A. Ribaldi (1999): The DEM of Mt. Etna: geomorphological and structural implications, Geodin. Acta, 12 (5), 279-290.

Favalli, M., M.T. PAReschi, A. Neri and I. Isola (2005): Forecasting lava flow paths by a stochastic approach, Geophys. Res. Lett., 32, L03305, doi: 10.1029/ $2004 \mathrm{GL} 021718$.

Favalli, M., G. Chirico, P. Papale, M.T. Pareschi, M. Coltelli, N. Lucaya and E. Boschi (2006a): Computer simulations of lava flow paths in the town of Goma, Nyiragongo volcano, Democratic Republic of Congo, J. Geophys. Res., 111, B06202, doi: 10.1029/ 2004JB003527.

Favalli, M., M.T. Pareschi and G. Zanchetta (2006b): Simulation of syn-eruptive floods in the circumvesuvian plain (Southern Italy), Bull. Volcanol., 68, doi: 10.1007/s00445-005-0011-z, 349-362.

Gallant, J.C., I.D. Moore, M.F. Hutchinson and P.E. GESSLER (1994): Estimating fractal dimension of profiles: a comparison of methods, Math. Geol., 26 (4), 455-481.

Ganas A., S. Pallides and V. Karastathis (2005): DEMbased morphometry of range-front escarpments in Attica, Central Greece, and its relation to fault slip rates, Geomorphology, 65, 301-319.

Guzzetti, F. and P. REICHENBACH (1994): Towards a definition of topographic division of Italy, Geomorphology, 11, 57-74.

Guzzetti, F., M. Marchetti and P. Reichenbach (1997): Large alluvional fans in the north-central Po Plain (Northern Italy), Geomorphology, 18, 119-136.

Guzzetti, F., A. Carrara, M. Cardinali and P. ReichenBACH (1999): Landslide hazard evaluation: a review of current techniques and their application in a multi-scale study, Central Italy, Geomorphology, 31, 181-216.

Hutchinson, M.F. (1996): Australian Digital Elevation Mod- 
el (<http://cres.anu.edu.au/outputs/ausdem.php> accessed on July 2007).

Kenward, T., D.P. LetTenmaier, E.F. Wood and E. FieldING (2000): Effects of digital elevation models accuracy on hydrologic predictions, Remote Sensing Environ., 74, 432-444.

Kunni, A. and O.A. Pfiffner (2001): The relief of the Swiss Alps and adjacent areas and its relation to lithology and structure: topographic analysis from a $250-\mathrm{m}$ DEM, Geomorphology, 41, 285-307.

LiU, H., K.C. JezeK and B. Li (1999): Development of an Antarctic digital elevation model by integrating cartographic and remotely sensed data; a geographic information system based approach, J. Geophys. Res., 104 (10), 23199-23213.

Macedonio, G. and M.T. Pareschi (1991): An algorithm for the triangulation of arbitrarily distributed points: applications to volume estimate and terrain fitting, Comput. Geosci., 17, 859-874.

MARTZ, L.W. and J. GARBREChT (1995): Automated recognition of valley lines and drainage networks from grid digital elevation models: a review and a new method Comment, J. Hydrol., 167 (1-4), 393-396.

MAseroli, R. (2002): Passaggio tra sistemi di riferimento geodetici. La nuova procedura adottata dall'IGM, Boll. Geod. Sci. Affini, 61 (2), 81-82.

Mazzarini, F., M.T. PARESChi, M. Favalli, I. Isola, S. TARQUINI and E. BoschI (2005): Morphology of basaltic lava channels during the Mt. Etna September 2004 eruption from airborne laser altimeter data, Geophys. Res. Lett., 32, L04305, doi: 10.1029/ 2004GL021815.

MoORE, I.D., R.B. GraYSON and A.R. LADSON (1991): Digital terrain modelling: a review of hydrological, geomorphological and biological applications, Hydrol. Processes, 5, 3-30.

NED-USGS (2000): US GeoData Digital Elevation Models (<http://erg.usgs.gov/isb/pubs/factsheets/fs14899.html> accessed on July 2007).

Onorati, G., M. Poscolieri, R. Ventura, V. Chiarini and U. CRUCILla (1992): The digital elevation model of Italy for geomorphology and structural geology, Catena, 19 (2), 147-178.

Pareschi, M.T., M. Favalli, F. Giannini, R. Sulpizio, G. ZANChETTA and R. SANTACroce (2000a): May 5, 1998, Debris flows in circumvesuvian areas (Southern Italy), insights for hazard assessment, Geology, 28 (7), 639-642.

Pareschi M.T., L. Cavarra, M. Favalli, F. Giannini and A. MERIGGI (2000b): GIS and Volcanic Risk management, Nat. Hazard, 21, 361-379.

Pareschi, M.T., R. Santacroce, R. Sulpizio and G.
ZANCHETTA (2002): Volcanoclastic debris flows in the Clanio Valley (Campania, Italy): insight for the assessment of hazard potential, Geomorphology, 43, 219-231.

PIKE, R.J. and W.J. Rozema (1975): Spectral analysis of landforms, Ann. Assoc. Am. Geogr., 65 (4), 449-516.

Pike, R.J., F. Guazzetti, R.K. Mark, G. Bortoluzzi, M. Ligi, B. BennetT, W. Acevedo and G.P. Thelin (1990): Synoptic maps of Italy's topography from a digital elevation model, in Atti del I Workshop 'Informatica e Scienze della Terra', October 18-20, 1989, Sarnano (NA), Italy, 1-7.

Reichenbach, P., R.J. Pike, W. Acevedo and R.K. Mark (1993): A new landform map of Italy in computershaded relief, Boll. Geod. Sci. Affini, 52 (1), 21-44.

Stevens, N.F., G. Wadge and J.B. Murray (1999): Lava flow volume and morphology from digitized contour maps: a case study at Mt. Etna, Sicily, Geomorpholo$g y, \mathbf{2 8}, 251-261$.

Stevens, N.F., V. Manville and D.W. Heron (2003): The sensitivity of a volcanic flow model to digital elevation model accuracy: experiments with digitised map contours and interferometric SAR at Ruapehu and Taranaki volcanoes, New Zealand, J. Volcanol. Geotherm. Res., 119, 89-105.

SuRACE, L. (1997): La nuova rete geodetica nazionale IGM95: risultati e prospettive di utilizzazione, Boll. Geod. Sci. Affini, 56 (3), 357-377.

SwISstopo (2001): Swiss Federal Office of Topography. Product Information (<http://www.swisstopo.ch> accessed on July 2007).

SzÉKELY, B. and D. KARÁtSON (2004): DEM-based morphometry as a tool for reconstructing primary volcanic landforms: examples from the Börzsöny Mountains, Hungary, Geomorphology, 63, 25-37.

Watson, D.F. (1981): Computing the $N$-dimensional Delaunay tessellation with application to Voronoi polytopes, Comput. J., 24 (2), 167-172.

WEAVER, H.J. (Editor) (1983): Applications of Discrete and Continuous Fourier Analysis (John Wiley, New York), pp. 387.

ZHANG, W. and D. MonTGOMERY (1994): Digital elevation model grid size, landscape representation, and hydrologic simulations, Water Resour. Res., 30 (4), 1019-1028.

Zhou, Q. and X. LiU (2004): Analysis on errors of derived slope and aspect related to DEM data properties, Comput. Geosci., 30 (4), 369-378.

(received April 20, 2007; accepted September 20, 2007) 